\title{
INTEREST RATE RISK IN TURKISH FINANCIAL MARKETS ACROSS DIFFERENT TIME PERIODS
}

\author{
Durmuş Özdemir ${ }^{1}$ \\ Harald Schmidbauer $^{2}$
}

\begin{abstract}
A measuring the risk associated with interest rates is important since it is beneficial in taking measures before negative effects can take place in an economy. We obtain a risk measure for interest rates by fitting the generalized Pareto distribution (GPD) to positive extreme day-to-day changes of the interest rate, using data from the Istanbul Stock Exchange (ISE) Second Hand Bond Market, namely Government Bond interest rate closing quotations, for the time period 2001 through 2009. Although the use of the GPD in the context of absolute interest rates is well documented in literature, our approach is different insofar and contributes to the literature as changes in interest rates constitute the target of our analysis, reflecting the idea that risk arises from abrupt changes in interest rate rather than in interest rate levels themselves. Our study clearly shows that the GPD, when applied to interest rate changes, provides a good tool for interest rate risk assessment, and permit a period-specific risk evaluation.
\end{abstract}

Keyword: Interest rate risk; covered interest parity; Turkey; generalized Pareto distribution

\author{
JEL Classification: G1; C1
}

1 Corresponding author: Istanbul Bilgi University, Department of Economics, Dolapdere Campus, Kurtuluș, Deresi Cad., Yahya Köprüsü Sok.No: 1, 34440 Beyoğlu, Istanbul, Turkey, Tel.+902123115326, Fax+902122970134, E-mail: dozdemir@bilgi.edu.tr.

2 Department of Business Administration, Bilgi University, Santral Campus, Eski Silahtarağa Elektrik Santrali, Kazım Karabekir Cad. No: 2/13, 34060 Eyup, Istanbul, Turkey, Tel.+902123117789, E-mail: harald@hs-stat.com. 


\section{INTRODUCTION}

The risk expresses the chance of occurrence of an undesired event or events and nonaccrual of an intended and/or planned expectation. In an economic sense risk is the probability of a monetary loss regarded with a transaction or loss resulting due to decreasing financial returns. Cyclical fluctuations and price changes can increase the risk of occurrence of the undesired situations.

Risk is divided into two as systemic and systematic risks. All securities in financial markets are subject to systematic risks, and systematic risks arise for example when fluctuations within political and economic conditions affect the behavior of assets in financial markets. As a result systematic risks are unavoidable in the sense that keeping them under control in a way is impossible. Systemic risks on the other hand are risks related with controllable processes such as intra-firm investment risks or a risk that may be likely to occur due to a decision on a financial issue (Turanlı, Özden and Demirhan (2002)).

Interest rate risk should therefore be considered within the context of systematic risks. The fluctuations in interest rates could not totally be controlled but some measures may be taken or certain tools may be applied to cope with interest rate risk.

Measuring the interest rate risk is important since it may be beneficial in taking measures before negative effects can take place in an economy (see Woodford (1999)). From the perspective of finance interest rate should be considered not only with economy but with many other factors as well. According to Ang and Bekaert (2002), risk hidden in the behavior of interest rates has a direct effect on the functioning of markets. Duffie and Kan (1996) and Dai and Singleton (2002) show that interest rates not only affect the functioning of markets but also have the power to alter the structure of the markets.

There are many other perspectives as well. For example financial income perspective says that the income going to be generated in the future is effected by interest rates because today's value calculation is made by an assumed interest rate level. If there is an unexpected change in the interest rates there is a risk that the value of income may be lower than expected. From an institutional perspective, changes in interest rates affect a financial institution's market value (Carneiro and Sherris (2008)). Because the value of a financial institution's assets and liabilities on the one hand and off-balance-sheet contracts written on interest rates on the other are affected by a change in rates, the present value of future cash flows and in some cases even the cash flows themselves can change.

The focal point of the present study is to measure the interest rate risk in the Turkish spot market for government bonds. We will first look at what has happened in the Turkish economy within the period under investigation (2001- 2009). After this we will look at the statistical properties of changes in the daily series of interest rates. 
Our analysis is based on the tail index of the generalized Pareto distribution (GPD), applied to threshold excesses of changes in interest rate series. The tail index characterizes whether the underlying distribution has heavy tails. A similar approach (however, applied to interest rate figures themselves, not to changes of rates) was used by Bali and Neftci (2001) in order to compute a VaR for interest rates in the American market. Meyfredi (2005) has used the estimation of risk measures associated with fat tails for stock market returns in several countries. The behaviour of joint threshold exceedances of returns on international stock indices is investigated by Schmidbauer and Rösch (2004). They show how a bivariate GPD can contribute to financial risk assessment among markets in bull and bear periods.

Gencay, Selçuk and Ulugulyağcı (2002) applied this setting to data from Istanbul Stock Exchange and derive a VaR measure meant to be an alert system for the market. Gencay and Selcuk (2001) had already applied a similar methodology for overnight interest rates of Turkish money markets in order to derive a measure querying whether the ex-ante interest overnight levels are indicators of the 2001 crisis or not.

Next section outline the literatures study and the underlying theory on interest rate. Section 3 discuss the data and methodology, while section 4 provide result and analysis. Conclusion will be provided on last section and concludes the study.

\section{THEORY}

Many factors may determine the shape of interest rate distribution. From micro level behaviour, macro aggregated, and external factors including negative shock may change the dynamics of interest rate; gradually or drastically. On international perspective, the rule of covered interest provides basic relationship among interest rate, exchange rate, and inflation.

Common dynamic of interest rate is well recognized, one of them is that the interest rate volatilities is stochastic. It is also recognized that interest rate tends to cluster, particularly when shifting form low to high volatility; see Andersenand Lund (1997) in Allan Sall Tang Andersen (2011).

Borodin and Strokov (2011), investigates the interrelations between the interest rates and international trade within the BRIC countries, and found that countries with lower interest rates experience growth of the share of machinery industry exports rather than agriculture and food products, and, on the contrary. On the other hand, in countries with higher interest rates, the share of agriculture and food exports increases and the share of machinery industry products declines. The investigation has shown that a relative shift in the interest rate can affect the specialization of countries.

David Andolfatto (2012) used simple neoclassical model and show that liquidity shock at home and foreign potentially contribute to trade imbalances and push down the interest rate, which is claimed to be inline with Bernanke's global saving glut hypothesis. 
Turner (2014) noticed many advanced countries including the FED, Bank of Japan and the Bank of England purchase government bonds on a massive scale to lower the long-term interest rate, and to stimulate aggregate demand. It shows low long-term rate has recently become an important intermediate target of central banks in the advanced economies, which affect the short term rate as well. The relationship between the exchange rate, short term rate, and long term interest rate may be illustrated as follows:

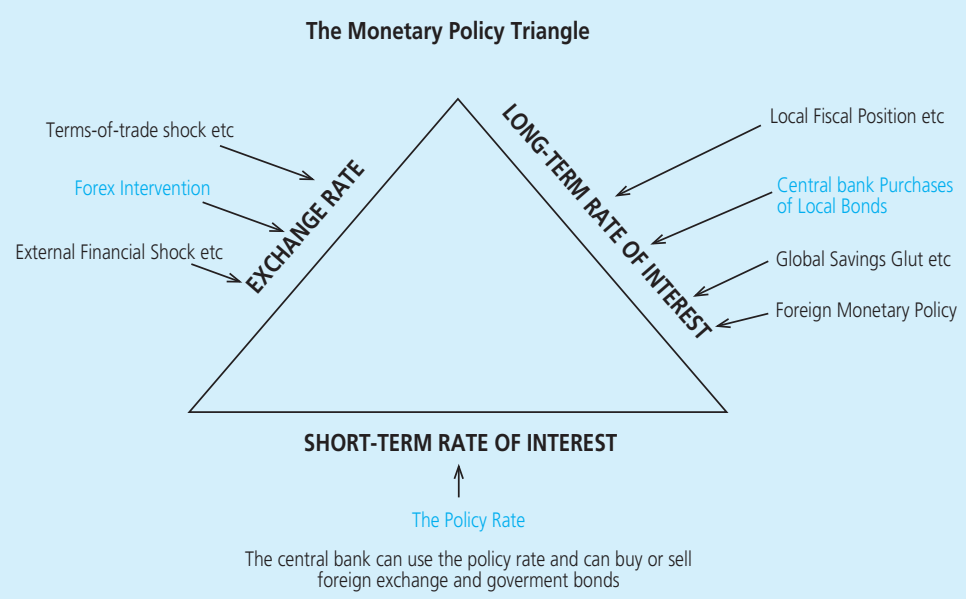

In a more formal formulation, Conway and Orr (2002) construct a global interest rate model (GIRM) based on the concept of efficient debt markets, where by any arbitrage opportunity is exploited by global investors. This model indentify three categories of the determinants of interest rate dynamics; economic fundamentals, short run deviations of bond yields from their long run levels, and global financial integration.

Desroches and Francis (2007) identify the behaviour of the world real interest rate which is determined by a number of key variables that change relatively slowly over time. They include the growth of labour force, which affects investment demand, and the age structure of the world economy, which influences savings, and also the level of financial development. Recently, Abbritti, Salvatore, Moreno, and Sola (2013) use FAVAR model to model the global term structure. Using panel of international yield curves, they show that global factors account for more than 80 percent of term premia in advanced economies, while domestic factors are more relevant to explain the short-run dynamics of the rate.

Those factors explained above will determine the shape of interest rate, which is appearing to have a fat tail distribtution. Fisher and Tippett (1928) originally introduced the traditional 
method for modeling extreme-value data is based on the extreme-value limiting distributions. Pickands (1975) introduced the Generalized Pareto Distribution (GPD) as a two parameter family of distributions or exceedances over a threshold. Later on there other studies extended the theory such as the article by Hosking and Wallis (1987). Use of GPD in economics is mainly done in last decade. Bali and Neftci (2001), Gencay and Selcuk (2004), Gencay, Selçuk and Ulugulyagcı (2002), Sčhmidbauer and Rösch (2004) and Meyfredi (2005) are to name a few.

Carr and Wu (2007) show that currency options have time-varying skewness. By using model-free estimates of the volatility and skewness priced in interest-rate options, it can be shown that interest rate distributions also show time-varying skewness (see Trolle and Schwartz (2010)). The main purpose of the paper is to provide a consistent framework for modeling the stochastic volatility and skewness. Finally, calibrating the model to time-series of the market data is interesting, as it shows the applicability of the model.

\section{METHODOLOGY}

\subsection{The Generalized Pareto Distribution (GPD)}

Let $\left(i_{t}\right)$ designate a daily series of interest rates ( $t$ indicates the day), and define the series of daily changes as

$$
r_{t}=\frac{i_{t}-i_{t-1}}{i_{t-1}} \cdot 100 \%
$$

The focal point of this paper is to study the upper threshold exceedance behaviour of the series $\left(r_{t}\right)$ on the basis of the generalized Pareto distribution (GPD), which is a model for excesses of a random variable. The rationale behind using the GPD is a limit theorem which states $^{3}$ : Let $r_{1}, \ldots, r_{n}$ be iid random variables, and let $R$ be distributed like $r_{i}$. Then, for large $n$ and $u$, there are $\xi$ and $\sigma$ such that the distribution function of the excess $(r-u)$ conditional on $R>U$, is approximately given by:

$$
\mathrm{F}(\mathrm{x} ; \xi, \sigma)=\left\{\begin{array}{cc}
1-\left(1+\xi \frac{\mathrm{x}}{\sigma}\right)^{-1 / \xi} & ; \text { if } \xi \neq 0 \\
1-\exp \left(-\frac{\mathrm{x}}{\sigma}\right) & ; \text { if } \xi=0
\end{array}\right\}
$$

3 For example, see Coles (2001). 
Here, $\sigma>0$ is a scale parameter; it depends on the threshold and on the probability density function of $r_{i}$. The shape parameter $\xi$ is called the tail index, since it characterizes the tail of the density function:

- The case $\xi>0$ corresponds to fat-tailed distributions; in this case, the GPD reduces to the Pareto distribution.

- The case $\xi=0$ corresponds to thin-tailed distributions; the GPD then reduces to the exponential distribution with mean $\sigma$.

- The case $\xi<0$ corresponds to distributions with no tail (i.e. finite distributions).

- When $\xi=1$, the GPD becomes a uniform distribution on the interval $[0, \sigma]$.

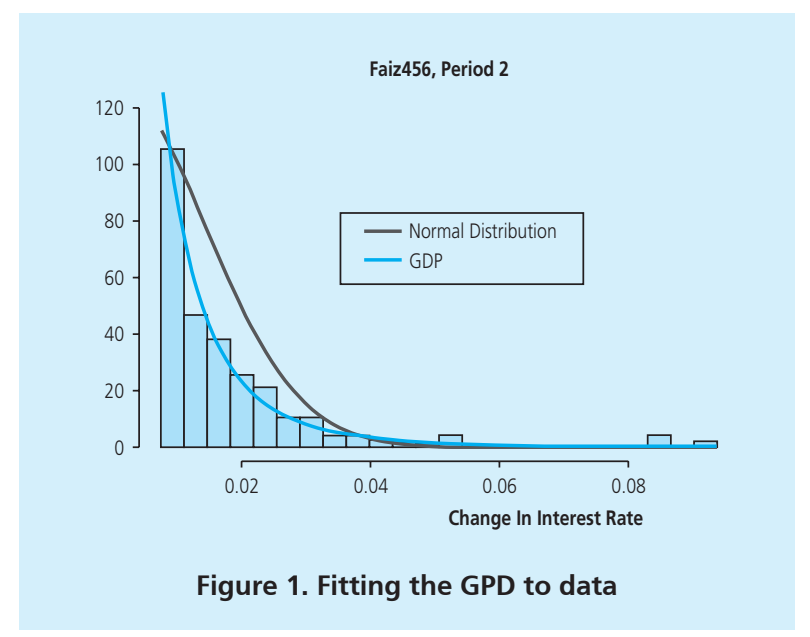

A typical example of fitting the GPD to the upper tail of one of the ( $\left.r_{-} t\right)$ series under consideration is shown in Figure 1. The histogram represents the upper tail of the empirical distribution of daily changes in the series interest rate (456 daily closing quotations of interest rates to maturity government bonds trading at the ISE Bounded Bond Purchasing Market; faiz456) during period 2), where we used the $80 \%$ quintile as cutoff point. This quintile was used as cut off point through out our study. The red line is the density of the normal distribution with the same mean and variance as faiz456 in period 2, and the green line is the density of the GPD fitted to the data. It is obvious that the normal distribution overestimates the probability of moderate changes and underestimates the probability of large changes. This makes it inappropriate for risk analysis in our case.

Computationally, we use the package "evd" (see Stephenson, 2002) within the statistic software environment $R$ (The $R$ Core Team, 2013) tofit the GPD to data. The estimation method implemented in "evd" is maximum likelihood. Standard errors were cross-checked using bootstrap to ensure the reliability of results. 


\subsection{Data}

We use daily closing quotations of interest rates of 90, 182, 273, 365 and 456 days to maturity government bonds trading at the ISE Bounded Bond Purchasing Market. The periode of analysis covers January 2001 to December 2009. This data is available upon request from ISE.

Prior the application of GPD method, we identify the presence of structural break over the observation horizon. The investigation provides us four periods. A plot of the series is shown in Figure 2 for the four periods under investigation. There are no corporate bonds in this market. The Turkish Bond Market is dominated by Treasury Bonds.

\section{RESULT AND ANALYSIS}

\subsection{Structural Breaks in the Interest Rate Series}

We shall now approach the question of how to divide the period under consideration into sub-periods by applying a statistical test for structural changes to the time series of daily interest rates. This will provide further arguments for a separate risk analysis in the three subperiods. ${ }^{4}$ In addition, we will clearly see the limitations of regression models when applied to the interest rate series.

The method we use will find breakpoints in a regression relationship, with interest rates as dependent variable and time (i.e. day) as independent variable. This method is based on Bai and Peron (2003); its implementation is described in Zeileis, Kleiber, Kramer and Hornik (2003). Breakpoints are computed with the objective of minimizing the residual sum of squares under the constraint that no segment should be shorter than 15\% of total time period considered.

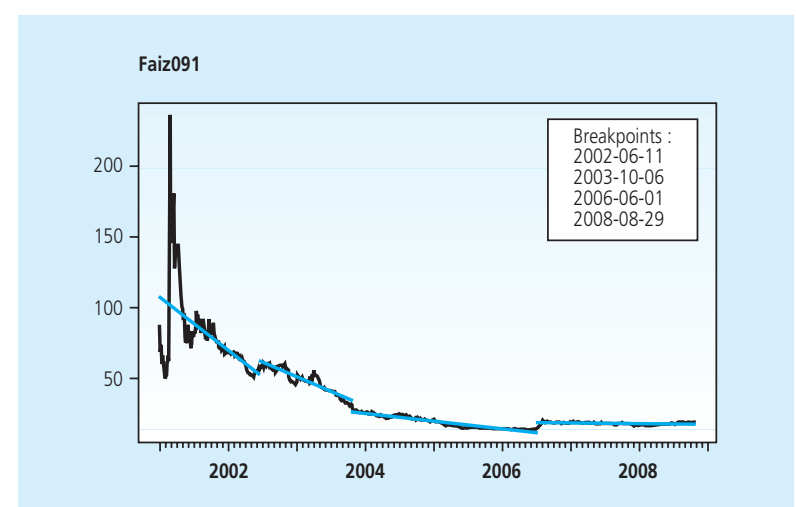

Figure 2. Breakpoint analysis of faiz0915

4 We analyzed the period January 2001 through August 2008, based on structural breaks. The subsequent period, here called Period 4 , was adjoined for economic reasons.

5 Faiz091 is a daily closing quotations of interest rates of 90 days to maturity government bonds trading at the ISE Bounded Bond Purchasing Market. 
(Our time series, beginning with January 2001 and ending in August 2008, are 1930 days long). The number of breakpoints is not predetermined, but results from the procedure.

The test for structural changes finds four breakpoints in the series faiz091, which we chose for this purpose to represent interest rate evolution. The results of the breakpoint analysis are displayed in Figure 3. In our subsequent analysis, we shall ignore the first breakpoint and form period 1 with 2003-10-06 as last day. This is justified because of the relative homogeneity of circumstances and events in this period. We are there fore led to a definition of sub-periods and their characterization as shown in Table 1.

\subsection{Characteristics of the Sub-Periods}

First of all, it is justifiable to separate this whole period into only two periods: the period until 2002, and the period from 2003 through 2009. Starting from the beginning of 2001 and ending with the end of 2002 there were three events that mainly shaped this period: the economic crises experienced on 28 February 2001, the September 11, 2001; and the Turkish General Elections in November 2002. The period was comprised of many instabilities in terms of both economy and politics throughout the period (see Insel, 2003).

\begin{tabular}{l|c|c|l}
\multicolumn{2}{|c}{ Dividing the period January 2001 - December 2009 into sub-periods } \\
Period & Start & End & \multicolumn{1}{c}{ Characteristic } \\
Period 1 & $2001-01-02$ & $2003-10-06$ & $\begin{array}{l}\text { Table 1 } \\
\text { high interest rates, decreasing rapidly after peak; large } \\
\text { daily fluctuations }\end{array}$ \\
\hline Period 2 & $2003-10-07$ & $2006-06-01$ & $\begin{array}{l}\text { more moderate interest rates, decreasing; small daily } \\
\text { fluctuations }\end{array}$ \\
\hline Period 3 & $2006-06-02$ & $2008-08-29$ & $\begin{array}{l}\text { moderate interest rates at a relatively stable level; } \\
\text { moderate daily fluctuations }\end{array}$ \\
\hline Period 4 & $2008-09-01$ & $2009-12-31$ & $\begin{array}{l}\text { similar to period 3, but higher "surprise potential" due } \\
\text { to higher kurtosis }\end{array}$
\end{tabular}

Between 2003 and 2008, a growth of 7\% growth was seen in the Turkish economy on the average. Per capita GDP had increased by $30 \%$, the domestic currency has revalued $30 \%$ as well. On the other hand a $100 \%$ set back was seen on trade and balance of payments deficit. Inflation dropped to $12 \%$ from $40 \%$, while the interest rate level dropped to a figure of $21 \%$ from a rate of $76 \%$ at the end of $2001^{6}$.

6 All quoted figures are taken from: Banking Regulation and Supervision Agency (BDDK) Financial Markets Report, March-June 2006, Number 1-2. Available online at http://www.bddk.org.tr/english/Reports/Financial Markets Report/1971fprMart Haziran2006ingilizce. pdf. Accessed October 2008. 


\section{The period between January 2001 and September 2003}

As mentioned above this period was stricken with economic and political instabilities. The resolution which authorized the Turkish National Assembly to send troops to Iraq was approved with a 50\% majority on 2003-10-06. According to the news expressed the day after this was perceived as a manifestation of "political integrity" by the markets".

It should also be mentioned that the inflation was reported to be the lowest in 30 years in October $2003^{8}$. Shortly afterwards the Treasury explained a debt structuring in the sense of swapping the short term government bonds with longer maturities. Interest rates had dropped 200 basis points, and the Turkish Government was subsequently able to borrow for longer term. ${ }^{9}$

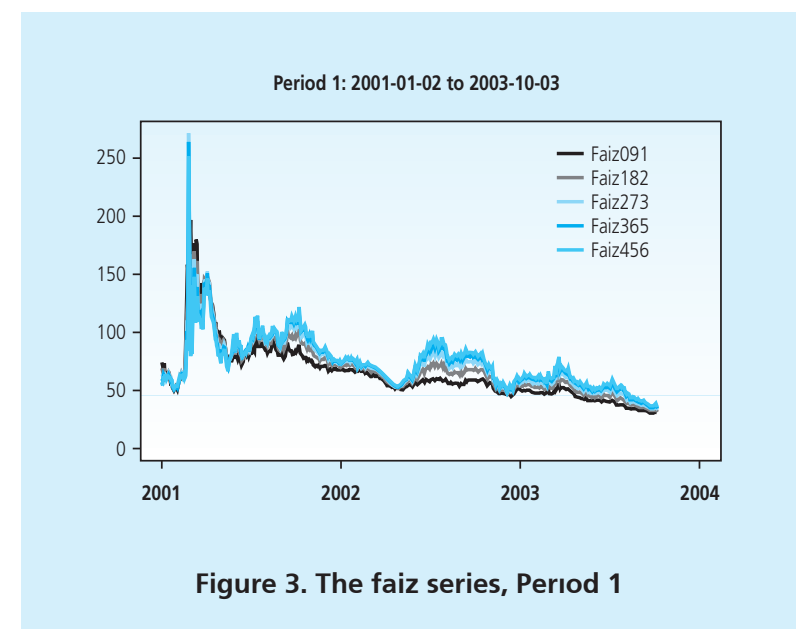

\section{The Period between October and May 2006}

There were four main events 2003 shaping this period: WTO abolished trade barriers, capital flows rendered more liberalised, growth of developed economies had increased, and inflation in developed countries.

It can be said that this period was a period of capital flows between diverse markets. Total volume of capital circulation throughout the world had reached approximately $\$ 15$ trillion

7 Hurriyet Online: "TezkereGeçti Asker IrakaGidiyor, Kabul 358 Red 183", date: 2003-10-07. Available online at http://webarsiv. hurriyet.com.tr/2003/10/07/hurriyetim.asp. Accessed October 2008.

8 Hurriyet Online: "Enflasyona Eylül Çelmesi", date: 2003-10-04. Available online at http://webarsiv.hurriyet.com.tr/2003/10/03/ hurriyetim.asp. Accessed October 2008.

9 Hurriyet Online: "Para KuruluToplandı", date: 2003-10-15. Available online at http://webarsiv. hurriyet.com.tr/2003/10/15/hurriyetim. asp. Accessed October 2008. 


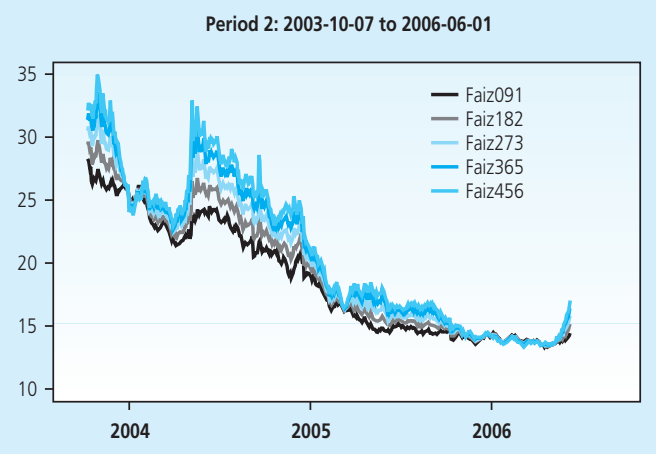

Figure 4. The faiz series, Period 2

according to the IMF Economic Outlook ${ }^{10}$. Developing countries in this sense were also among the beneficiaries. An amount of $\$ 2$ trillion out of $\$ 15$ trillion had flown to them, Turkey's share being $\$ 90$ by foreign investment, according to the Turkish Central Bank Inflation Report ${ }^{11}$.

\section{The Period between 2006-06-02 and 2008-08-29}

There were four main events that shaped the period ${ }^{12}$ : inflation fear of developed countries, the increase in interest rates, the sub-prime crises through the end of the year 2007, and the banking crises throughout the world.
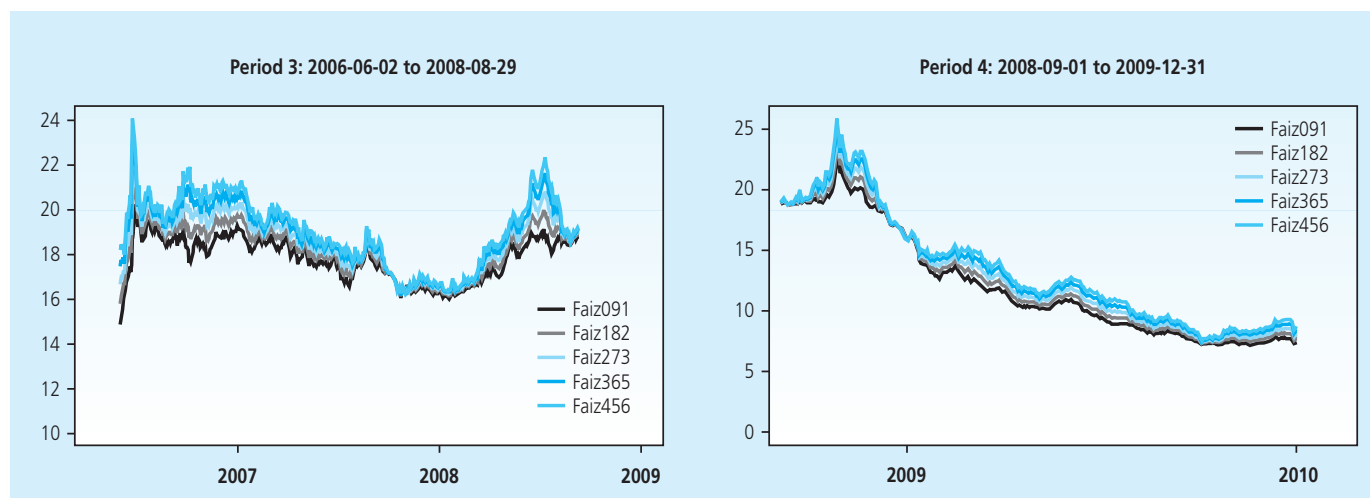

Figure 5. The faiz series, Period 3 and 4

10 International Monetary Fund (IMF) World Economic Outlook, October 2006, pp. 1-6. Available online at http://www.imf.org/ external/pubind.htm.Accessed October 2008.

11 Turkish Central Bank, Inflation Report 2006-IV, pp. 41-46. Available online at http://www.tcmb.gov.tr/.Accessed October 2008.

12 International Monetary Fund (IMF) World Economic Outlook, October 2008: Financial Stress, Downturns and Recoveries, pp. 1-46. Available online at http://www.imf.org/external/pubs/ft/weo/2008/02/pdf/text.pdf. Accessed October 2008. 


\subsection{Statistical Properties of Daily Interest Rate Changes}

Tables 4 and 5 in the Appendix give an analysis of the distributional properties of the percent point changes in the five series for the four periods in terms of mean, variance and standard deviation, skewness, kurtosis, minimum, median, and maximum. Our goal in the present paper is an evaluation of the interest rate risk. Therefore, the two most important items in the list are the variance and the kurtosis.

There are obvious differences between the periods: The range of daily changes is widest for period 1; the variance and the kurtosis are largest for period 1. The behaviour of the five series within the periods gives insight into the characteristics of the different maturities, but also reveals further differences between the periods. In particular, some of the characteristics resulting from Tables 4 and 5 are:

- The arithmetic mean of the daily changes in the faiz series increases from faiz091 through faiz456 most pronouncedly in period 1 . An explanation may be that period 1 was regarded as risky by many investors in the sense that the Turkish financial market's risk premium is still high. As a consequence, investors demanded high long-maturity interest rates as a compensation for risks in future periods.

- The variance increases from faiz091 through faiz456 through out all periods, in other words: The interest rate risk increases with maturity.

- The tail behaviour of the distributions, as expressed in the kurtosis, is more complex. The kurtosis becomes larger as maturity increases only in period 1. This points again to an elevated risk for higher maturities in period 1. The results of Tables 4 and 5 point to a high risk in period 1, lower (and similar) risks in periods 2 and 3, and somewhat higher risk (albeit reduced "surprise potential", indicated by the lower kurtosis) in period 4. The kurtosis generally points to heavy tails in all periods across all series, with a few exceptions. The more complex kurtosis structure justifies using the GPD as a means to study the tail behaviour of the interest rate change distributions.

- The ratio between minimum and maximum percentage point change is increasing with maturity during periods $1,2,3$, with a reduced rate during period 4 . This is also clearly visible in the boxplots in Figure 4.

- $\quad$ The days when minima and maxima occurred is always the same or very close in period 1.

\subsection{GPD-Based Interest Rate Risk Measurement}

The estimation results are reported in Table 2. In our context of risk measurement, the estimated tail index $\xi^{\wedge}$ is more important than $\sigma^{\wedge}$. As stated above, a positive tail index indicates that the distribution of interest rate changes has a heavy upper tail (see Table 2). 
- Estimates of the GPD parameters $\xi$ and $\sigma$, together with their standard errors, based on daily interest rate changes (computed as $\left.r_{t}=\ln \left(i_{t}-i_{t-1}\right)\right)$ ) are above their empirical $80 \%$ quantile (that is, based on threshold exceedances of the $80 \%$ quantile) for each period,

- $\quad 95 \%$ and $99 \%$ quantiles of the interest rate changes (the columns designated as $\mathrm{q}_{95}$ and $\mathrm{q}_{99}$, respectively),

- $\quad$ The corresponding quantiles are obtained by adding a GPD-based quantile to the empirical $80 \%$ quantile (which served as the threshold).

The relatively close agreement between the latter pairs throughout the periods we considered and across the interest rate maturities can be seen as a confirmation of the model accuracy.

A comparison of the four periods with respect to the tail properties of the interest rate change distribution leads to the following remarks:

- Period 1 has exceptionally high values of $\xi$ for each interest rate series considered: All five tail indices are significantly positive (which indicates heavy tails, here: an elevated risk that tomorrow's interest rate is much higher than today's) at the $5 \%$ level of significance.

- There is little difference between Periods 2 and 3, as far as the tail index is concerned. None of the interest rate change distributions is heavy-tailed, with the exception of faiz456. This points to an elevated overnight increase in interest rate only for long-term bonds.

- $\quad$ The exceptional status of faiz456 has disappeared in Period 4.

- The normal distribution is not appropriate to measure the risk associated with interest rates in Turkey. The GPD, derived as an explicit model for distribution tails, fits very well and provides a close fit between the theoretical VaRs and empirical quantiles.

\subsection{Discussion}

In this section we will try to discuss the economic implications of our study to explain how our study fits into economic arguments. We have examined the interest rate risk in the Turkish economy. Statistical modelling is the key to the development of such risk scores. There are many economic reasons to have different levels of risks in interest rates. Statistical risk scores can make a useful contribution to economic decision making under uncertainty. A general assumption of a decision or action depends on the occurrence of some adverse event, and that we have data which indicate how the likelihood of this event depends on values of observable risk factors. 
Period 1

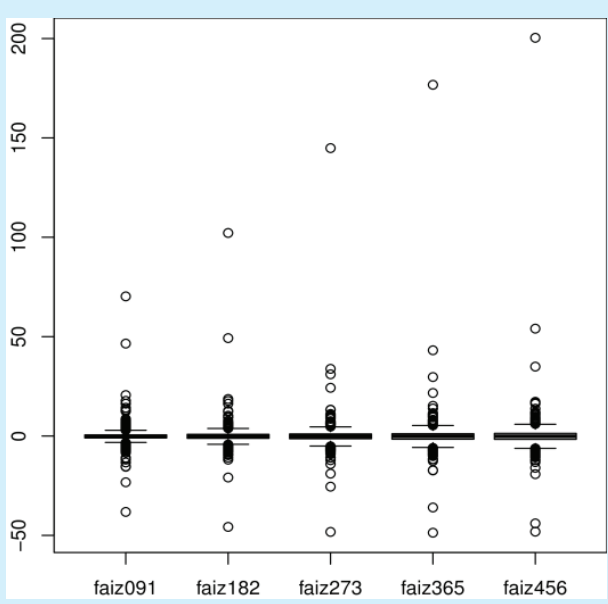

Period 3

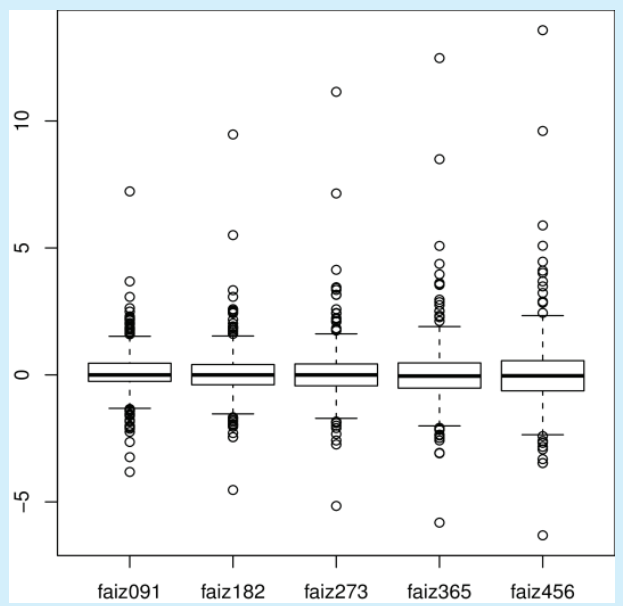

Period 2

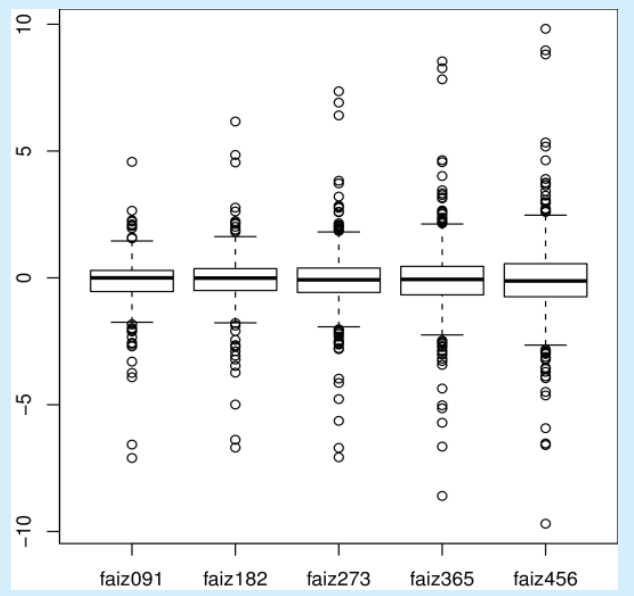

Period 4

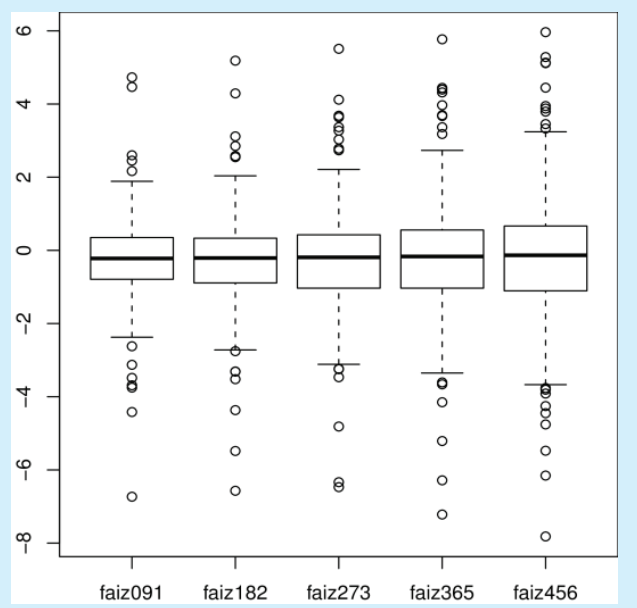

Figure 6. Boxplots of Interest Rate Changes, Four Periods

A risk indicator can be provided by the examination of extreme values of interest rates in the framework of extreme value theory. Extreme value theory is a powerful framework to study the tail behaviour of a distribution; hence it can be a good indicator for risk. 


\begin{tabular}{|c|c|c|c|c|c|c|c|c|}
\hline \multicolumn{9}{|c|}{$\begin{array}{c}\text { Table } 2 \\
\text { Parameters of fitted GPDs }\end{array}$} \\
\hline \multicolumn{3}{|c|}{${ }^{\wedge} \xi$ std.err. ${ }^{\wedge} \xi$} & n $\sigma$ & \multicolumn{2}{|c|}{ std.err. ^ $\sigma$} & q.95 5\% VaR & \multicolumn{2}{|c|}{ q.99 1\% VaR } \\
\hline \multicolumn{9}{|c|}{ period 1: 2001-01-02 - 2003-10-06 (692 observations) } \\
\hline faiz091 & 0.6213 & 0.1404 & 0.0120 & 0.0018 & 0.0347 & 0.0346 & 0.1185 & 0.1133 \\
\hline faiz182 & 0.5195 & 0.1283 & 0.0143 & 0.0021 & 0.0404 & 0.0402 & 0.0988 & 0.1141 \\
\hline faiz273 & 0.4886 & 0.1265 & 0.0168 & 0.0024 & 0.0520 & 0.0474 & 0.1028 & 0.1283 \\
\hline faiz365 & 0.4155 & 0.1156 & 0.0211 & 0.0029 & 0.0569 & 0.0553 & 0.1044 & 0.1412 \\
\hline faiz456 & 0.3993 & 0.1131 & 0.0236 & 0.0032 & 0.0614 & 0.0607 & 0.1144 & 0.1532 \\
\hline \multicolumn{9}{|c|}{ period 2: 2003-10-07 - 2006-06-01 (666 observations) } \\
\hline faiz091 & 0.0000 & 0.0565 & 0.0047 & 0.0005 & 0.0101 & 0.0107 & 0.0197 & 0.0184 \\
\hline faiz182 & 0.0000 & 0.0469 & 0.0062 & 0.0007 & 0.0119 & 0.0127 & 0.0213 & 0.0227 \\
\hline faiz273 & 0.0000 & 0.0444 & 0.0077 & 0.0009 & 0.0151 & 0.0157 & 0.0278 & 0.0281 \\
\hline faiz365 & 0.0000 & 0.0449 & 0.0091 & 0.0011 & 0.0183 & 0.0189 & 0.0332 & 0.0336 \\
\hline faiz456 & 0.2796 & 0.1129 & 0.0073 & 0.0010 & 0.0214 & 0.0201 & 0.0373 & 0.0419 \\
\hline \multicolumn{9}{|c|}{ period 3: 2006-06-02 - 2008-08-29 (569 observations) } \\
\hline faiz091 & 0.0000 & 0.0480 & 0.0065 & 0.0007 & 0.0126 & 0.0141 & 0.0224 & 0.0246 \\
\hline faiz182 & 0.0000 & 0.0325 & 0.0067 & 0.0007 & 0.0120 & 0.0144 & 0.0251 & 0.0252 \\
\hline faiz273 & 0.0000 & 0.0311 & 0.0077 & 0.0009 & 0.0136 & 0.0160 & 0.0317 & 0.0284 \\
\hline faiz365 & 0.2990 & 0.1044 & 0.0058 & 0.0008 & 0.0155 & 0.0164 & 0.0353 & 0.0347 \\
\hline faiz456 & 0.3056 & 0.1068 & 0.0065 & 0.0009 & 0.0166 & 0.0184 & 0.0396 & 0.0389 \\
\hline \multicolumn{9}{|c|}{ period 4: 2008-09-01 - 2009-12-31 (332 observations) } \\
\hline faiz091 & 0.0000 & 0.0687 & 0.0057 & 0.0009 & 0.0108 & 0.0123 & 0.0232 & 0.0215 \\
\hline faiz182 & 0.0000 & 0.0843 & 0.0067 & 0.0011 & 0.0140 & 0.0151 & 0.0272 & 0.0259 \\
\hline faiz273 & 0.0000 & 0.1149 & 0.0085 & 0.0015 & 0.0165 & 0.0183 & 0.0348 & 0.0320 \\
\hline faiz365 & 0.0000 & 0.1303 & 0.0097 & 0.0018 & 0.0207 & 0.0215 & 0.0411 & 0.0371 \\
\hline faiz456 & 0.0000 & 0.1436 & 0.0113 & 0.0020 & 0.0236 & 0.0249 & 0.0476 & 0.0431 \\
\hline
\end{tabular}

For this study we use the generalized Pareto distribution (GPD) to asses the interest rate risk for the period starting in 2001 till the end of 2009. Estimating GPDs to the data resulted in a good fit between the model and our data for all periods and maturities. It turned out 
that the tail indices, indicating the weight of the upper tail of distributions of daily interest rate changes, became smaller and smaller, indicating that tails became thinner from period to period (except for the maturities second period faiz456 and faiz456, faiz356 on period3), thus reducing interest rate risk.

As summarized in Figure 3, the interest rates have three significant structural brakes in this period. Due to justifiable economic reasons, the entire period is divided into four sub-cycles. These cycles are important because, for example, during recession consumers are likely to cut back on luxury items, and thus firms in the consumer durable goods sector should see their credit risk increased. Moreover, there is considerable evidence that macroeconomic conditions impact the emergence of risk. For example, during economic crises reduced (or even negative) growth will slow down the adjustment speed of capital. Economic agents borrow less. Thus GDP growth is positively associated with the likelihood of debt issue (see Hackbarth, Miao and Morellec (2006)).

Keeping this argument in mind, in our sample periods, the highest risk is in the first period with a highest value of $\xi$. As far as high risk is concerned, the first period is followed by the third period, but the only risky periods of borrowings are the longer maturity borrowings, i.e. a year or more maturity borrowings. The second period, starting with 2003-07-10 and ending in 2006-06-01, has zero $\xi$ values except for the longest maturity (faiz456). A general economic rule applying here is that the longer is the maturity, the more risk will emerge. Period 4 shows zero $\xi$ values for all maturity levels, which indicates that this period is associated with a lowest interest rate risk period. This result appeared to be contradictory at the beginning because this period is the first period of the impact of the global financial crisis on the Turkish economy.

An obvious question is, why does an economic crisis affect the risk associated with interest rates in Turkey? An interpretation of this result can be found in the macroeconomic implications of an economic crisis. During global crises, price levels and the level of interest rates will generally decrease. Prices decrease because of lowering demand for goods, and the rates of interest will also decrease for a similar reason. Compared to the earlier periods, in the fourth period, the sensitivity of interest rates with respect to investment decreases, implying a reduced demand for loans.

Figure 5 depicts the weekly observations of the total consumer loans and the claims under legal proceedings between 2004-06-25 and 2010-01-01. It is very clear that the consumer borrowing demand is slowing down for the latest period, and there is a dramatic increase in the claims under legal proceedings. Hence the decrease in the risk of the rates of interest for this period is smaller than expected.

These interpretations are statistically confirmed by the results of Table 3: Statistical properties of interest rate changes for the four periods indicate that the results are significant. Higher kurtosis means that a larger share of the variance is due to infrequent extreme deviation, as opposed to frequent modestly sized deviations. 
Table 3

Joint threshold exceedances

period 1: 2001-01-02 - 2003-10-06

\begin{tabular}{rr|rr} 
& & \multicolumn{2}{|c}{$Y$} \\
& & 1 & 0 \\
\hline$X$ & 1 & 43 & 97 \\
& 0 & 97 & 455
\end{tabular}

odds ratio :

2.08

95\% confidence interval :

$[1.37,3.16]$

period 2: 2003-10-07 - 2006-06-01

\begin{tabular}{rr|rr} 
& & \multicolumn{2}{|c}{$Y$} \\
& & 1 & 0 \\
\hline$X$ & 1 & 34 & 100 \\
& 0 & 100 & 432
\end{tabular}

odds ratio :

95\% confidence interval :

$[0.94,2.29]$

period 3: 2006-06-02 - 2008-08-29

\begin{tabular}{rr|rr} 
& & \multicolumn{2}{|c}{$Y$} \\
& & 1 & 0 \\
\hline$X$ & 1 & 31 & 83 \\
& 0 & 83 & 372
\end{tabular}

odds ratio :

95\% confidence interval :

$[1.04,2.69]$

period 4: 2008-09-01 - 2009-12-31

\begin{tabular}{rr|rr} 
& & \multicolumn{2}{|c}{$Y$} \\
& & 1 & 0 \\
\hline$X$ & 1 & 18 & 48 \\
& 0 & 47 & 217
\end{tabular}

odds ratio :

95\% confidence interval :
1.73

$[0.93,3.22]$ 


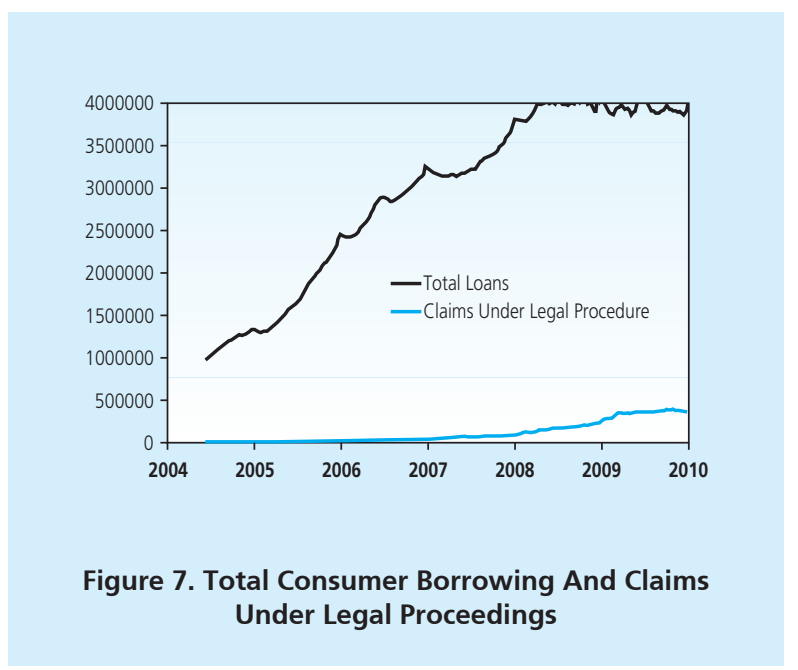

Moreover, our results are also in line with the covered interest parity link. Table 3 depicts the joint threshold exceedances for our four sub-periods in the Turkish economy. We have used the dollar TL exchange rate as a proxy measure of the Turkish exchange rate. The joint behaviour of changes in Turkish interest rates and the USD/TL is in line with our approach to interest rate risk assessment to investigate the occurrence of joint daily threshold exceedances. For each period, we define indicator variables as follows:

$$
\begin{aligned}
& X t=\left\{\begin{array}{l}
1 \text { If a USD-return exceedance happened on day } t, \\
0 \text { Otherwise, }
\end{array}\right. \\
& Y t=\left\{\begin{array}{l}
1 \text { If an interest rate change exceedance happened on day } t, \\
0 \text { Otherwise, }
\end{array}\right.
\end{aligned}
$$

Here, we speak of a USD-return exceedance if the change in price of a USD in TL was larger than its $90 \%$ quantile or lower than its $10 \%$ quantile, where the quantile is periodspecific. Likewise, an interest rate change exceedance is said to happen if the change in interest rate is larger than its $90 \%$ quantile or lower than its $10 \%$ quantile, where quantiles are again period-specific. Contingency tables for $X$ and $Y$, together with their odds ratios, are shown in Table 3. An odds ratio larger than 1 indicates a positive association of $X$ and $Y$, that is, the main diagonal of the contingency table has higher frequencies than expected under the hypothesis that $X$ and $Y$ are independent.

Table 3 reveals that, as expected, a positive association was found for all periods, the odds ratio indicating the strongest link for Period 1 . Furthermore, a significantly positive association (at a significance level of 5\%) was only found for periods 1 and 3 . Any interest rate exceedance 
will also entail a change in interest rates. This link is similar for all four periods. Thus we observe a covered interest parity condition in Turkish financial markets.

\section{CONCLUSION}

Measuring the interest rate risk is important for the emerging markets as well as the globalised financial system. A risk hidden in the behavior of interest rates has not only directly effect the functioning of markets but also have the power to alter the structure of the markets. It is obvious that the normal distribution overestimates the probability of moderate changes and underestimates the probability of large changes. This makes it inappropriate for risk analysis in our case.

The use of the GPD in the context of absolute interest rates is well documented in literature, our approach is different insofar as changes in interest rates constitute the target of our analysis, reflecting the idea that risk arises from abrupt changes in interest rate rather than in interest rate levels themselves. Our study clearly shows that the GPD, when applied to interest rate changes, provides a good tool for interest rate risk assessment, and permit a period-specific risk evaluation. 


\section{APPENDIX: STATISTICAL PROPERTIES OF INTEREST RATE CHANGES}

\begin{tabular}{|c|c|c|c|c|c|c|c|c|c|c|}
\hline \multicolumn{11}{|c|}{$\begin{array}{c}\text { Table } 4 \\
\text { Statistical properties of interest rate changes, four periods }\end{array}$} \\
\hline & Faiz091 & Faiz182 & Faiz273 & Faiz365 & Faiz456 & Faiz091 & Faiz182 & Faiz273 & Faiz365 & Faiz456 \\
\hline \multicolumn{6}{|c|}{ Period 1 : 2001-01-02 - 2003-10-06 (692 obs.) } & \multicolumn{5}{|c|}{ Period 3 : 2006-06-02 - 2008-08-29 (569 obs.) } \\
\hline Mean & -0.06 & -0.00 & 0.07 & 0.14 & 0.20 & 0.05 & 0.04 & 0.04 & 0.04 & 0.03 \\
\hline std error & 0.16 & 0.23 & 0.27 & 0.28 & 0.33 & 0.03 & 0.04 & 0.04 & 0.05 & 0.06 \\
\hline Var & 21.04 & 30.36 & 47.56 & 66.06 & 83.40 & 0.71 & 0.80 & 1.03 & 1.35 & 1.70 \\
\hline std deviaton & 4.59 & 5.51 & 6.90 & 8.13 & 9.13 & 0.84 & 0.90 & 1.02 & 1.16 & 1.31 \\
\hline Skewness & 5.92 & 9.46 & 13.13 & 14.67 & 15.22 & 1.09 & 2.40 & 3.00 & 2.98 & 2.82 \\
\hline std error & 3.70 & $5 \mathrm{~m} 17$ & 6.66 & 7.32 & 7.76 & 0.87 & 1.36 & 1.28 & 1.22 & 1.13 \\
\hline Kurtosis & 102.35 & 184.97 & 283.47 & 322.95 & 334.71 & 10.96 & 24.74 & 30.26 & 29.05 & 26.44 \\
\hline std error & 39.15 & 67.89 & 118.18 & 127.24 & 139.63 & 5.33 & 11.98 & 13.83 & 11.51 & 11.83 \\
\hline \multicolumn{6}{|c|}{ Period 2 : 2003-10-07 - 2006-06-01 (666 obs.) } & \multicolumn{5}{|c|}{ Period 4 : 2008-09-01 - 2009-12-31 (332 obs.) } \\
\hline Mean & -0.10 & -0.10 & -0.10 & -0.09 & -0.09 & -0.28 & -0.26 & -0.25 & -0.24 & -0.22 \\
\hline std error & 0.04 & 0.04 & 0.04 & 0.06 & 0.05 & 0.06 & 0.07 & 0.08 & 0.09 & 0.09 \\
\hline Var & 0.73 & 0.91 & 1.29 & 1.76 & 2.24 & 1.16 & 1.45 & 1.89 & 2.43 & 3.03 \\
\hline std deviaton & 0.85 & 0.96 & 1.14 & 1.33 & 1.50 & 1.08 & 1.20 & 1.37 & 1.56 & 1.74 \\
\hline Skewness & -1.62 & -0.52 & 0.17 & 0.42 & 0.49 & -0.52 & -0.38 & -0.24 & -0.17 & -0.11 \\
\hline std error & 0.78 & 0.75 & 0.69 & 0.73 & 0.61 & 0.67 & 0.51 & 0.37 & 0.35 & 0.23 \\
\hline Kurtosis & 13.71 & 11.46 & 11.02 & 10.69 & 10.10 & 6.35 & 4.51 & 3.19 & 2.46 & 2.06 \\
\hline std error & 4.27 & 2.59 & 1.81 & 2.31 & 2.21 & 2.24 & 1.22 & 0.91 & 0.74 & 0.61 \\
\hline
\end{tabular}




\begin{tabular}{|c|c|c|c|c|c|}
\hline \multicolumn{6}{|c|}{$\begin{array}{c}\text { Table } 5 \\
\text { Quantiles of interest rate changes, four periods }\end{array}$} \\
\hline & faiz091 & faiz182 & faiz273 & faiz365 & faiz456 \\
\hline \multicolumn{6}{|c|}{ period 1: 2001-01-02 - 2003-10-06 (692 observations) } \\
\hline Min & 38.20 & 45.74 & 48.25 & 48.66 & 48.13 \\
\hline median & 0.10 & 0.13 & 0.16 & 0.14 & 0.13 \\
\hline Max & 70.25 & 102.17 & 144.86 & 176.72 & 200.37 \\
\hline day of $\min$ & $2001-02-26$ & $2001-02-26$ & $2001-02-26$ & $2001-02-26$ & $2001-02-26$ \\
\hline day of max & $2001-02-20$ & $2001-02-23$ & $2001-02-23$ & $2001-02-23$ & $2001-02-23$ \\
\hline \multicolumn{6}{|c|}{ period 2: 2003-10-07 - 2006-06-01 (666 observations) } \\
\hline Min & 7.09 & 6.73 & 7.05 & 8.59 & 9.70 \\
\hline median & 0.00 & 0.02 & 0.07 & 0.07 & 0.13 \\
\hline $\max$ & 4.58 & 6.20 & 7.34 & 8.56 & 9.81 \\
\hline day of min & 2004-09-08 & $2004-12-20$ & 2004-05-12 & 2004-05-12 & 2004-05-12 \\
\hline day of max & $2004-05-10$ & $2004-05-10$ & 2004-05-10 & 2004-09-20 & 2004-09-20 \\
\hline \multicolumn{6}{|c|}{ period 3: 2006-06-02 - 2008-08-29 (569 observations) } \\
\hline Min & 3.80 & 4.55 & 5.17 & 5.84 & 6.32 \\
\hline median & 0.00 & 0.00 & 0.00 & 0.00 & 0.05 \\
\hline $\max$ & 7.24 & 9.48 & 11.16 & 12.49 & 13.55 \\
\hline day of $\min$ & 2006-07-04 & 2006-07-04 & 2006-07-04 & $2006-07-04$ & 2006-07-04 \\
\hline day of max & 2006-06-26 & $2006-06-26$ & $2006-06-26$ & $2006-06-26$ & $2006-06-26$ \\
\hline \multicolumn{6}{|c|}{ period 4: 2008-09-01 - 2009-12-31 (332 observations) } \\
\hline Min & 6.73 & 6.57 & 6.47 & 7.22 & 7.82 \\
\hline median & 0.22 & 0.21 & 0.19 & 0.17 & 0.13 \\
\hline $\max$ & 4.73 & 5.18 & 5.51 & 5.77 & 5.96 \\
\hline day of min & 2009-01-16 & 2009-01-16 & 2009-01-16 & 2009-12-29 & $2009-12-29$ \\
\hline day of max & $2008-10-27$ & $2008-10-27$ & $2008-10-27$ & $2008-10-27$ & $2008-10-27$ \\
\hline
\end{tabular}




\section{REFERENCES}

Andolfatto, David. 2012. Liquidity Shocks, Real Interset Rates, and Global Imbalances, Federal Reserve Bank of St. Louis, Review, May/June 2012, 94 (3), pp. 187-95.

Ang, A., and Bekaert, G. 2002. International asset allocation with regime shifts. The Review of Financial Studies 15, 1137-1187.

Bai, J., and Peron, P. 2003. Computation and analysis of multiple structural change models. Journal of Applied Econometrics 18, 1-22.

Bali, T.G., and Neftçi, S.N. 2001. Estimating the term structure of interest rate volatility in extreme values. Journal of Fixed Income, March 2001. Available at SSRN: http://ssrn.com/ abstract=262418.

Brigitte Desroches and Michael Francis. 2007. Global Savings, Investment, and World Real Interest Rates, Bank of Canada Review, winter, 2006-2007.

Carneiro, L.A. F., and Sherris, M. 2008. Corporate interest rate risk management with derivatives in Australia: Empirical results. Revista Contabilidade \& Financas 19, 86-107.

Coles, S. 2001.An Introduction to Statistical Modeling of Extreme Values. Springer, Berlin.

Dai, Q., and Singleton, K.J, 2002. Specification analysis of affine term structure models. Journal of Finance LV, 1943-1978.

Duffie, D., and Kan R, 1996. Yield factor model of interest rates. Mathematical Finance 6, 379-406.

Fisher, R.A. and Tippett, L.H.C. 1928. Limiting forms of the frequency distribution of the largest and smallest member of a sample,Proc. Camb. Phil. Soc.24, 80-190.

Gençay, R., and Selçuk, F. 2006. Overnight borrowing, interest rates and extreme value theory. European Economic Review 50, 547-563.

Gençay, R., Selçuk, F., and Ulugülyağcl, A. 2002. High volatility, thick tails and extreme value theory in value at risk estimation, Insurance: Mathematics and Economics 33, 337-356

Gençay, R., and Selçuk F. 2004. Extreme value theory and value at risk: Relative performance in emerging markets. Journal of Forecasting 20, 287-303. 
Hackbarth, D., and Miao, J., and Morellec, E. 2006. Capital structure, credit risk, and macroeconomic conditions. Journal of Financial Economics 82, 519- 550.

Hosking, J. R. M., and Wallis, J. R. (1987), "Parameter and Quantile Estimation for the GeneralizedPareto Distribution," Technometrics, 29, 339-349.

Insel, A. 2003. The AKP and normalising democracy in Turkey. The South Atlantic Quarterly 102, 293-308.

Konstantin Borodin and Anton Strokov. 2011. Central bank Interest Rate and International Trade in BRIC Countries: Agriculture vs. Machinery Industry?, conference paper on "Will the „BRICs Decade continue?-Prospects for Trade and Growth”, Halle (Saale), Germany.

Meyfredi, J. 2005.Is There a Gain to Explicitly Modelling Extremes? Working Paper, Edhec Risk and Asset Management Research Centre Publications, Nice.

Mirko Abbritti, Salvatore Dell'Erba, Antonio Moreno, andSergio Sola. 2013. Global Factors in the Term Structure of Interest Rates, International Monetary Fund, working paper, WP/13/223, November.

Paul Conway and Adrian Orr. 2002. The GIRM: A Global InterestRate Model, occasional paper, Westpac Institutional Bank.

Philip Turner. 2014. The global long-term Interest Rate, Financial Risks and Policy Choices in EMEs, BIS Working Papers, No. 441

Pickands, J. (1975), "Statistical Inference Using Extreme Order Statistics," The Annals of Statistics, 3,119-131.

R Core Team 2013R: A language and environment for statistical computing. R Foundation for Statistical Computing, Vienna, Austria. URL http://www.R-project.org/.

Schmidbauer, H., and Rösch, A. 2004. Joint threshold exceedances of stock index returns in bull and bear periods. Central European Journal of Operations Research 12, 197-209.

Stephenson, A.G. 2002. evd: Extreme Value Distributions. R News 2, 31-32.

Turanlı, M., andOzden, H.U., and Demirhan, D. 2002.SeçimTartışmalarının

Hisse Senedi Piyasalarına Etkisi, Istanbul Ticaret Universitesi Dergisi 2.

Woodford, M. 1999.Optimal Monetary Policy Inertia. NBER Working Papers 7261, Cambridge, Massachusetts.

Zeileis, A., and Kleiber, C., and Kramer W., and Hornik, K. 2003. Testing and dating of structural changes in practice. Computational Statistics and Data Analysis 44, 109-123. 